\title{
A prospective clinical study of foetomaternal outcome in relation to oligohydramnios in pregnancies beyond 36 weeks of gestation
}

\author{
B. S. Meena, Nimisha Gupta*, Oby Nagar, Swati Trivedi
}

Department of Obstetrics and Gynecology, RUHS, Jaipur, Rajasthan, India

Received: 04 April 2020

Accepted: 29 April 2020

*Correspondence:

Dr. Nimisha Gupta,

E-mail: guptanimi93@gmail.com

Copyright: (C) the author(s), publisher and licensee Medip Academy. This is an open-access article distributed under the terms of the Creative Commons Attribution Non-Commercial License, which permits unrestricted non-commercial use, distribution, and reproduction in any medium, provided the original work is properly cited.

\begin{abstract}
Background: Amniotic fluid is contributed by both mother and foetus. It plays a vital role in foetal growth. The main purpose of this study was to evaluate the foetomaternal outcome in pregnant females with oligohydramnios beyond 36 weeks of gestation.

Methods: This study was conducted on 230 pregnant females beyond 36 weeks of gestation with decreased liquor clinically and confirmed sonographically. It was conducted from May 2018 to May 2019. Females with leaking per vaginum, patients who did not give consent and with intrauterine foetal death were excluded. Complete labour record was made. Assessment of maternal outcome was done in terms of mode of delivery and foetal outcome was done in terms of birth weight, Apgar score at one and five-minute, respiratory distress, meconium aspiration, seizures in first 24 hours of life, congenital malformations, neonatal intensive care unit admission and death of baby.

Results: A total of 230 pregnant females met the inclusion criteria who were having AFI <5. $121(53 \%)$ females were primigravida and $119(52 \%)$ underwent for caesarean section. Most common indication of LSCS was foetal distress. Apgar score at 1 minute was $<7$ in $97(42 \%)$ babies and after 5 minutes, it was $<7$ in $93(40 \%)$ babies. Other neonatal outcome results were IUGR in $59(26 \%)$ babies, meconium aspiration syndrome in $52(23 \%)$ babies, respiratory distress in $92(40 \%)$ babies, congenital malformation in $6(3 \%)$ babies, NICU admission of 93 (40\%) babies and neonatal death of $11(5 \%)$ babies.
\end{abstract}

Conclusions: Oligohydramnios increases the chances of maternal morbidity and perinatal morbidity and mortality.

Keywords: Amniotic fluid index, Apgar score, Oligohydramnios, Single vertical pocket

\section{INTRODUCTION}

The amniotic fluid is contributed by both mother and foetus. ${ }^{1}$ Its volume is controlled by the interactions among foetal, placental and maternal compartments. ${ }^{2}$ It is composed of both organic and inorganic compounds which help in the growth of the foetus. It is alkaline in nature having a specific gravity of $1.010 .^{3}$ Initially, dye dilution method was used which is a standard method to measure amniotic fluid volume. Currently, it is not practiced as it is being found an invasive one. So, other methods including single deepest vertical pocket (SVP) method by Chamberlain and amniotic fluid index (AFI) by Phelan are being used., ${ }^{4,5}$ Oligohydramnios is defined as $\mathrm{AFI}<5$ or $\mathrm{SVP}<2$. Its incidence is 1 to $5 \%$ of total pregnancies. ${ }^{6}$ It is caused by maternal conditions like hypertension, post-term pregnancy which affect blood supply towards foetus and cause a decrease in amniotic fluid production. Drugs like ACE inhibitors, NSAIDS affect foetal urine production. Foetal malformations like hydronephrosis, renal agenesis, polycystic kidney, chromosomal abnormalities can also cause oligohydramnios. There is an increased blood flow towards brain rather than kidneys in growth restricted babies, ultimately, leading to decrease urine production. ${ }^{7}$ Oligohydramnios increases maternal morbidity by 
increasing the rate of caesarean section and thus increases blood loss and infection and perinatal morbidity by causing limb deformities, cord compression leading to passage of meconium and meconium aspiration syndrome, lower Apgar scores, intensive care unit admission and neonatal mortality..$^{8-9}$ Management depends on the period of gestation. When diagnosed before 36 weeks of gestation in the presence of normal anatomy and growth, then it can be managed expectantly by increasing maternal hydration and also with drugs like L-arginine which releases nitric oxide and thus causes vasodilation. Amnioinfusion is done to decrease the cord compression during pregnancy. After 36 weeks, delivery is conducted according to maternal and foetal indications.

\section{METHODS}

This study was being conducted in pregnant females beyond 36 weeks of gestation with decreased liquor clinically and confirmed sonographically. It was conducted for a period of one year from May 2018 to May 2019. 230 pregnant females participated in the study.

\section{Inclusion criteria}

- Pregnant females beyond 36 weeks of gestation

- Decreased liquor clinically and confirmed with ultrasonography

- Membranes should be intact.

\section{Exclusion criteria}

- Females with leaking per vaginum

- Patients who did not give consent

- Intrauterine foetal death.

After applying both the inclusion and exclusion criteria, 230 pregnant females beyond 36 weeks of gestation with decreased liquor clinically and confirmed sonographically, were selected. Informed and written consents were taken. These patients with oligohydramnios were admitted and delivered according to maternal and foetal condition. Complete labour record was made. Complete physical examination of both mother by obstetrician, and baby by paediatrician was done.

Assessment of maternal outcome in terms of mode of delivery and foetal outcome in terms of birth weight, Apgar score at one and five-minute, respiratory distress, meconium aspiration, seizures in the first 24 hours of life, congenital malformations, neonatal intensive care unit admission and death of baby was done in this study.

\section{Statistical analysis}

Linear variables were summarized as mean and standard deviation, whereas, nominal/categorical variables were presented as proportions (\%). Unpaired t test was used for analysis of linear variables and chi-square test and Fischer exact test were used for nominal/categorical variables. $\mathrm{p}$ value $<0.05$ was taken as significant. Medcale 16.4 version software was used for statistical calculations.

\section{RESULTS}

In a one year of study, there were 230 pregnant females who fulfilled the criteria. As per Table 1, it was found that most of the females $189(82 \%)$ were in between 21 to 30 years of age group and $121(53 \%)$ were primigravida. $129(56 \%)$ females were booked and belonged to middle socioeconomic status. Mostly females 202 (88\%) were Hindu and from urban areas 137 (57\%).

Table 1: Sociodemographic parameters of patients.

\begin{tabular}{|llll|}
\hline \multirow{2}{*}{ Characteristics } & & $\begin{array}{l}\text { No. of } \\
\text { patients }\end{array}$ & Percentage \\
\hline \multirow{2}{*}{ Age (in years) } & $<20$ & 12 & $5 \%$ \\
\cline { 2 - 4 } & 21 to 30 & 189 & $82 \%$ \\
\cline { 2 - 4 } & $>30$ & 29 & $13 \%$ \\
\hline \multirow{2}{*}{ Gravidity } & Primi & 121 & $53 \%$ \\
\cline { 2 - 4 } & Multi & 109 & $47 \%$ \\
\hline \multirow{2}{*}{ Booking status } & Booked & 129 & $56 \%$ \\
\cline { 2 - 4 } & Unbooked & 101 & $44 \%$ \\
\hline \multirow{2}{*}{ Residence } & Rural & 98 & $43 \%$ \\
\cline { 2 - 4 } & Urban & 132 & $57 \%$ \\
\hline \multirow{2}{*}{ Religion } & Hindu & 202 & $88 \%$ \\
\cline { 2 - 4 } & Muslim & 28 & $12 \%$ \\
\hline \multirow{2}{*}{$\begin{array}{l}\text { Socio- } \\
\text { economic status }\end{array}$} & Low & 101 & $44 \%$ \\
\cline { 2 - 4 } & Middle & 129 & $56 \%$ \\
\hline
\end{tabular}

Hypertension $62(27 \%)$ was the most common maternal condition associated with oligohydramnios followed by hypothyroidism, asthma, heart disease and diabetes. No cause was detected in $142(62 \%)$ of the pregnancies as shown in Table 2.

Table 2: Maternal conditions associated with oligohydramnios.

\begin{tabular}{|lll|}
\hline Maternal conditions & No. of cases & Percentage \\
\hline Hypertension & 62 & $27 \%$ \\
\hline Hypothyroidism & 23 & $10 \%$ \\
\hline Asthma & 1 & $0.4 \%$ \\
\hline Heart disease & 1 & $0.4 \%$ \\
\hline Diabetes & 1 & $0.4 \%$ \\
\hline $\begin{array}{l}\text { No associated maternal } \\
\text { condition }\end{array}$ & 142 & $62 \%$ \\
\hline
\end{tabular}

Table 3: Maternal outcome associated with oligohydramnios.

\begin{tabular}{|lll|}
\hline Mode of delivery & No. of patients & Percentage \\
\hline Vaginal delivery & 111 & $48 \%$ \\
\hline LSCS & 119 & $52 \%$ \\
\hline
\end{tabular}


Maternal outcome was assessed in terms of mode of delivery. There were $119(52 \%)$ females who underwent for caesarean section whereas 111 (48\%) delivered vaginally as seen in Table 3 . Most common indication of LSCS was foetal distress followed by failed induction.

Table 4: Foetal conditions associated with oligohydramnios.

\begin{tabular}{|lll|}
\hline Foetal condition & No. of cases & Percentage \\
\hline Growth Restriction & 59 & $26 \%$ \\
\hline Malpresentation & 18 & $8 \%$ \\
\hline Congenital malformation & 6 & $3 \%$ \\
\hline
\end{tabular}

As shown in Table 4, 59 (26\%) babies were growth restricted. Malpresentation was found in $18(8 \%)$ patients and 6 (3\%) were having malformations like hydronephrosis and polycystic kidney.

Table 5: Foetal outcome in oligohydramnios group.

\begin{tabular}{|lll|}
\hline Foetal outcome & No. of cases & Percentage \\
\hline $\begin{array}{l}\text { Apgar score }<7 \text { at } 1 \\
\text { minute }\end{array}$ & 97 & $42 \%$ \\
\hline $\begin{array}{l}\text { Apgar score }<7 \text { after } 5 \\
\text { minutes }\end{array}$ & 93 & $40 \%$ \\
\hline $\begin{array}{l}\text { Meconium aspiration } \\
\text { syndrome }\end{array}$ & 52 & $23 \%$ \\
\hline Respiratory distress & 92 & $40 \%$ \\
\hline Seizures & 2 & $1 \%$ \\
\hline NICU Admission & 93 & $40 \%$ \\
\hline Death & 11 & $5 \%$ \\
\hline
\end{tabular}

As shown in Table 5, there was poor foetal outcome in patients with oligohydramnios. Out of the 230 babies, 97 (42\%) babies had Apgar score <7 at 1 minute, 93 (40\%) had Apgar score $<7$ after 5 minutes. 52 (23\%) aspirated meconium and $92(40 \%)$ had respiratory distress and seizure occurred in $2(1 \%)$ babies. There were $93(40 \%)$ babies who were admitted in NICU and 11 (4.78\%) babies died after birth.

\section{DISCUSSION}

Pregnancies with oligohydramnios are high risk pregnancies. It can be diagnosed clinically and confirmed by ultrasonography. In this study, it was found that $53 \%$ of the pregnant females were primigravida and $47 \%$ were multigravida. In a study done by Ghimire et al, $58 \%$ were primigravida and $42 \%$ were multigravida. ${ }^{10}$ Garmel et al supported that $67 \%$ of women with oligohydramnios were nulligravida and Charu et al supported that $66 \%$ of women were nulligravida. ${ }^{11,12}$ There were $82 \%$ of the females which were in between 21 to 30 years of age in this study. Similarly, in a study done by Gita $G$ et al, there were $70.7 \%$ of the pregnancies belonged to 21 to 30 years age group and $87.4 \%$ in a study by Rizwan Ahmer et al. ${ }^{13,14}$ In this study, 52\% underwent for caesarean section. "LSCS was done in $80 \%$ patients in Ghimire et al, study whereas $42.8 \%$ underwent for caesarean delivery in a study done by Gita $\mathrm{G}$ et al and $40 \%$ in a study by Ahmer $\mathrm{R}$ et al. ${ }^{10,13,14}$ There were $26 \%$ growth restricted babies in this study. There were $12.7 \%$ growth restricted babies in a study by Tajinder $\mathrm{K}$ et al, in study by Ahmer $\mathrm{R}$ et al. ${ }^{14,15}$ No significant difference in birth weight was observed in Ghimire et al study. ${ }^{10}$ Casey BM et al and Manning et al reported IUGR in $24 \%$ and $36 \%$ babies, respectively. ${ }^{9,16}$ Hypertension was found in $27 \%$ of the females. Similar observations were seen in studies by Tajinder $\mathrm{K}$ et al, (17.5\%) and Ahmer $\mathrm{R}$ et al $27.78 \% .^{14,15}$ Malpresentation was seen in $7.8 \%$ of the pregnancies in the present study. It was present in $17 \%$ of the subjects in Gita $\mathrm{G}$ et al study. ${ }^{13}$ There were congenital malformations in $2.6 \%$ babies in the present study. It was 4.2\% in Gita G et al study, 3.33\% in Ahmer R et al study and $7.9 \%$ in a study by Tajinder $\mathrm{K}$ et al. ${ }^{13-15}$ Most common congenital anomaly in all the studies was of genitourinary system. Foetal outcome was assessed in terms of Apgar score $<7$ at 1 minute which was $42.17 \%$, Apgar score at 5 minute which was $40.43 \%$, meconium aspiration syndrome in $22.60 \%$ babies, respiratory distress in $40 \%$ of the babies and $1 \%$ babies had seizures. In a study conducted by Ghimire et al, low Apgar score was seen in $20 \%$ babies and meconium aspiration syndrome in $9 \%$ babies. $^{10}$

In Ahmer R et al study, 25\% babies had low Apgar score, in Manning et al $15 \%$ babies had Apgar score $<7 .{ }^{14,16}$ $40.43 \%$ babies got admitted in NICU. $7 \%$ got admitted in Casey BM et al study, 20\% in Ahmer R et al study, 20\% in Johnson et al study and $29.4 \%$ in Zhang $\mathrm{J}$ et al study and $58.8 \%$ in Kaur $\mathrm{T}$ et al study. ${ }^{9,14-16,18}$ In this study, $4.78 \%$ babies died. There were $12 \%$ neonatal deaths in oligohydramnios group in Ghimire et al, $9.9 \%$ in Chamberlain et al, $6.4 \%$ in Casey et al, $12.6 \%$ in Gita G et al, 7.2\% in Wolff et al studies. ${ }^{4,9,10,13,19}$

\section{CONCLUSION}

Oligohydramnios increases the incidence of maternal morbidity and perinatal morbidity and mortality.

Funding: No funding sources

Conflict of interest: None declared

Ethical approval: The study was approved by the Institutional Ethics Committee

\section{REFERENCES}

1. Queeran JT, Gadow EC. Polyhydramnios: chronic versus acute. Am J Obstet Gynecol. 1970;108:34952.

2. Magann EF, Doherty DA, Chauhan SP, Busch FW, Mecacci F, Morrison JC. How well do the amniotic fluid index and single deepest pocket indices (below the $3^{\text {rd }}$ and $5^{\text {th }}$ and above the $95^{\text {th }}$ and $97^{\text {th }}$ percentile) predict oligohydramnios and hydramnios? Am J Obstet Gynecol. 2004;190:164-9. 
3. Sowmya K, Varghese B, Borkar YB. Effect of isolated oligohydramnios in otherwise normal term pregnancy. Int J Biomed Res. 2014;5(2):98-101.

4. Chamberlain PF, Manning FA, Morrison I, Harman CR, Lange IR. Ultrasound evaluation of amniotic fluid volume. The relationship of marginal and decreased amniotic fluid volumes to perinatal outcome. Am J Obstet Gynecol. 1984;150(3):245-9.

5. Phelan JP, Ahn MO, Smith CU, Rutherford SE. Amniotic fluid index in normal human pregnancy. J Reprod Med. 1987;32:601-4.

6. Moore TR. Clinical assessment of amniotic fluid. Clin Obstet Gynaecol. 1997;40(2):303-13.

7. Yoshimura S, Masuzaki $\mathrm{H}$, Gotoh $\mathrm{H}$, Ishimara $\mathrm{T}$. Fetal redistribution of blood flow and amniotic fluid volume in growth retarded foetuses. Early Hum Dev. 1997;47:297.

8. Voxman EG, Tran S, Wing DA. Low amniotic fluid index as a predictor of adverse fetal outcome. J Perinatol. 2000:22(4):282-5.

9. Casey BM, McIntire DD, Bloom SL, Lucas MJ, Santos R. Pregnancy outcome after antepartum diagnosis of oligohydramnios at or beyond 34weeks gestation. Am J Obstet Gynecol. 2001:82(4);909-12.

10. Ghimire S, Ghimire A, Chapagain S, Paudel S. Pregnancy cases in patients with oligohydramnios after 28 weeks of gestation. Int J Adv Med Health Res. 2016;3:68-72.

11. Garmel SH, Chelmow D, Sha SJ, Roan JT, D'Alton ME. Oligohydramnios and the appropriately grown fetus. Am J Perinatol. 1997;14(6):359-63.

12. Jandial C, Gupta S, Sharma S, Gupta M. Perinatal outcome after antepartum diagnosis of oligohydramnios at or beyond 34 weeks of gestation. JK Sci. 2007;9(4):213-4.

13. Guin G, Punekar S, Lele A, Khare S. A prospective clinical study of feto-maternal outcome in pregnancies with abnormal liquor volume. J Obstet and Gynaecol India. 2011;61(6):652-5.

14. Ahmar R, Sadia P, Kumari S, Kumar M. Neonatal and maternal outcome in oligohydramnios: a prospective study. Int $\mathbf{J}$ Contemp Pediatr. 2018;5(4):1409-13.

15. Kaur T, Sood R. Feto-maternal outcome in pregnancies with abnormal AFI. J Dental Med Sci. 2016;15(4):31-5.

16. Manning FA, Hill LM, Platt LD. Qualitative amniotic fluid volume determination by ultrasound: Antepartum detection of intrauterine growth retardation. Am J Obstet Gynecol. 1981;139(3):2548.

17. Johnson JM, Chauhan SP, Ennen CS, Niederhauser A, Magann EF. A comparison of 3 criteria of oligohydramnios in identifying peripartum complications: a secondary analysis. Am J Obstet Gynecol. 2007;197(2):207.e1-7.

18. Zhang J, Troendle J, Meikle S, Klebanoff MA, Rayburn WF. Isolated oligohydramnios is not associated with adverse perinatal outcome. BJOG. 2004;111(3):220-5.

19. Wolff F, Schaefer R. Oligohydramnios-perinatal complications and diseases in mother and child. Geburtshilfe Frauenheilkd. 1994;54(3):139-43.

Cite this article as: Meena BS, Gupta N, Nagar O, Trivedi S. A prospective clinical study of foetomaternal outcome in relation to oligohydramnios in pregnancies beyond 36 weeks of gestation. Int $\mathbf{J}$ Reprod Contracept Obstet Gynecol 2020;9:2342-5. 